\title{
Erratum to: Evolutionary Conceptual Analysis: Faith Community Nursing
}

\section{Deborah Ziebarth}

Published online: 16 September 2014

(C) Springer Science+Business Media New York 2014

\section{Erratum to: J Relig Health DOI 10.1007/s10943-014-9918-z}

The original version of this article unfortunately contained a typo in Fig. 1. The corrected figure is given below as:

The online version of the original article can be found under doi:10.1007/s10943-014-9918-z.

D. Ziebarth $(\bowtie)$

Church Health Center/International Parish Nurse Resource Center, Memphis, TN, USA e-mail: ziebarthd@ churchhealthservices.org

D. Ziebarth

University of Wisconsin, Milwaukee, Milwaukee, WI, USA

e-mail: Ziebart2@uwm.edu 


\section{New Conceptual Model: Faith Community Nursing (FCN)}

A Method of Wholistic Health Care Delivery (Ziebarth, 2014)

Old Conceptual Model: Parish Nursing

(Solari Twadell, et al, 1991)

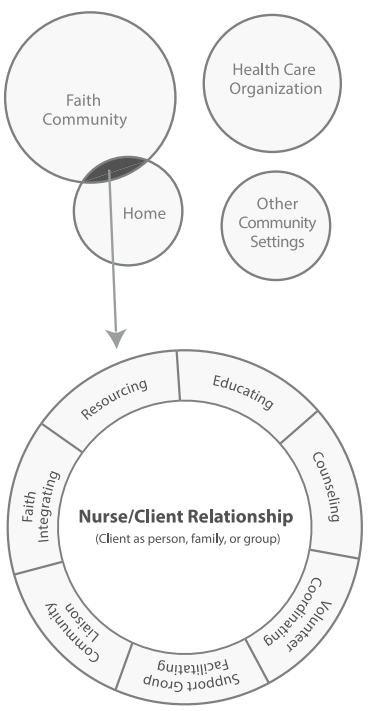

The resulting goal of the nurse-client

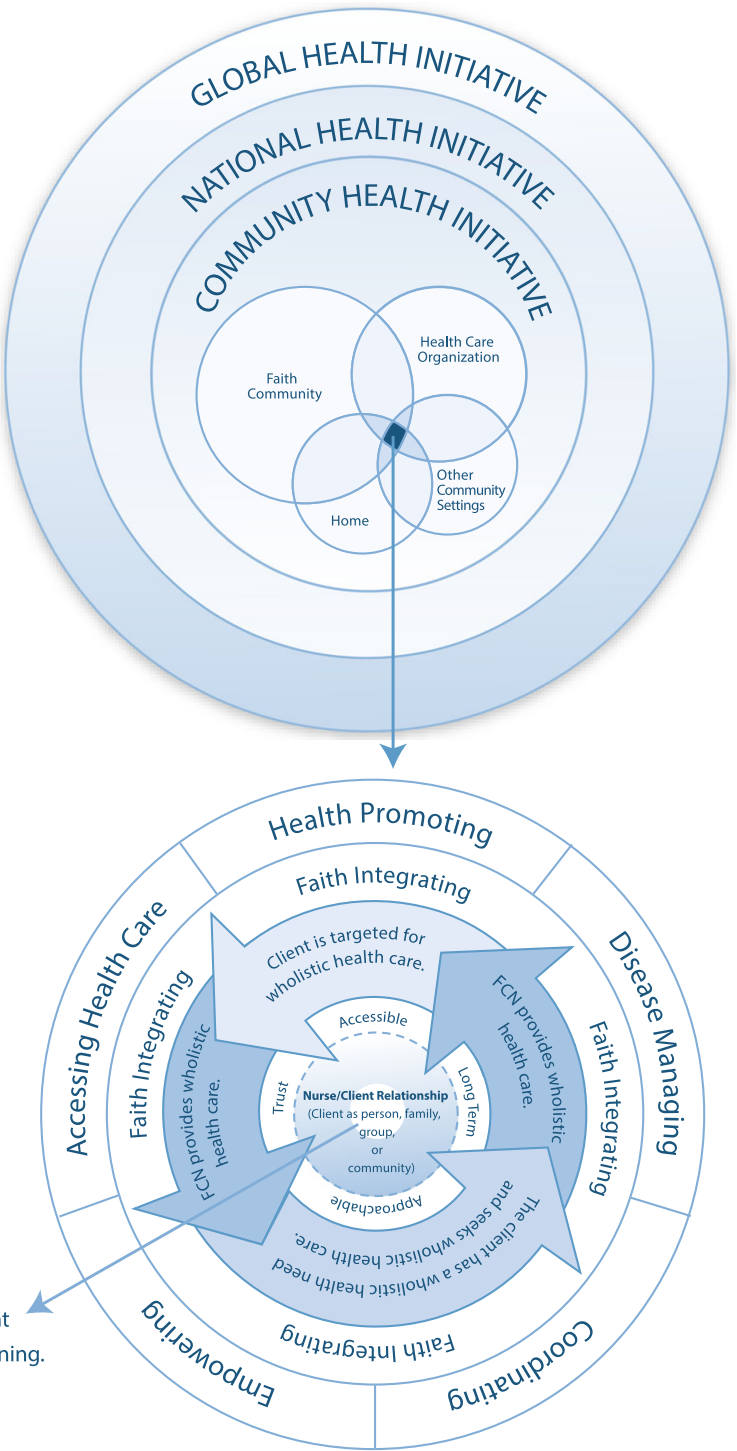

Fig. 1 New conceptual model: faith community nursing (FCN) 